\title{
EVALUASI ASPEK SOSIAL KEGIATAN PENANGKAPAN IKAN TUNA ( THUNNUS SP) OLEH NELAYAN DESA YAINUELO KABUPATEN MALUKU TENGAH
}

\author{
Erika Lukman \\ Staf Pengajar Faperta FPIK UNIDAR-Ambon, e-mail: -
}

\begin{abstract}
ABSTRAK
Ikan tuna (Thunnus sp) merupakan salah satu sumberdaya perikanan potensial di perairan Maluku Tengah dan banyak dimanfaatkan oleh nelayan dengan menggunakan berbagai jenis alat tangkap diantaranya pancing tangan (hand line), pancing tonda (trolling line), dan pukat cincin (purse seine). Penelitian ini bertujuan mengevaluasi aspek sosial kegiatan penangkapan ikan tuna dan kemungkinan pengembangannya di Desa Yainuelo. Penelitian ini dilaksanakan bulan November 2013. Sampel ditentukan dengan menggunakan metode purposive sampling berdasarkan pertimbangan bahwa nelayan responden adalah nelayan yang menangkap ikan tuna dengan menggunakan alat tangkap pancing tangan (hand line), pancing tonda (trolling line), dan pukat cincin (purse seine). Aspek sosial yang diteliti meliputi penerimaan nelayan terhadap suatu jenis alat tangkap, penyerapan tenaga kerja per unit penangkapan dari masing-masing alat tangkap, kemampuan nelayan menjangkau investasi unit penangkapan, dan tidak menimbulkan konflik. Hasil penelitian menunjukan bahwa kegiatan penangkapan ikan tuna dengan menggunakan alat tangkap pancing tonda dan pukat cincin dapat diterima secara sosial. Secara sosial standar nilai alat tangkap pancing tonda tertinggi 2,67 dan pukat cincin 2,65. Berdasarkan tinjauan dari aspek sosial alat tangkap terbaik untuk dikembangkan di Desa Yainuelo untuk penangkapan ikan tuna adalah alat tangkap pancing tonda (trolling line).
\end{abstract}

Kata Kunci: Ikan Tuna, Pancing Tangan, Pukat Cincin, Pancing Tonda, Aspek Sosial

\section{PENDAHULUAN}

1.1. Latar Belakang

Kabupaten Maluku Tengah adalah salah satu kabupaten dalam wilayah Provinsi Maluku. Dengan Luas Wilayah seluruhnya kurang lebih $275.907 \mathrm{Km}^{2}$ yang terdiri dari luas laut $264.311,43 \mathrm{Km}^{2}$ dan luas daratan $11.595,57$ $\mathrm{Km}^{2}$ ini artinya wilayah Kabupaten Maluku Tengah adalah wilayah dengan luas lautan sebesar 95,8 \% dari luas keseluruhannya. Wilayah ini memiliki potensi sumberdaya perikanan cukup besar. Salah satu sumberdaya perikanan potensial di perairan Kabupaten Maluku Tengah adalah ikan tuna. Nilai produksi ikan tuna pada tahun 2011 mencapai $7.547,10$ ton. Nilai ini mengalami peningkatan dari tahun sebelumnya yaitu $5.963,6$ ton (BPS,2012).
Ikan Tuna termasuk keluarga Scombridae, bentuk tubuhnya memanjang seperti cerutu atau torpedo, berwarna kebirubiruan atau biru tua, mempunyai dua sirip punggung, sirip depan biasanya pendek dan terpisah dari sirip belakang, serta mempunyai jari-jari sirip tambahan (finlet) di belakang sirip punggung dan dubur. Sirip dada terletak agak ke atas, sirip perut kecil, sirip ekor bercagak agak dalam dengan jari-jari penyokong menutup seluruh ujung hypural (Departemen Pertanian, 1983). Spesies tuna terdiri atas Thunnus madidihang, Thunnus albakora, Thunnus atlanticus, tuna mata besar (Thunnus obesus), dan tuna abu-abu (Thunnus tonggol). Perbedaan antar spesies terletak pada bentuk sirip dan warnanya. 
Desa Yainuelo terletak di Kecamatan Amahai Kabupaten Maluku Tengah, dengan luas Desa Yainuelo berdasarkan data monografi desa (2012) adalah $30 \mathrm{Ha}$, merupakan daerah pesisir yang potensial untuk kegiatan usaha penangkapan ikan. Alat tangkap yang biasa digunakan oleh masyarakat nelayan untuk menangkap ikan tuna cukup beragam dengan tingkat teknologi yang bervariasi seperti pukat cincin (purse seine), pancing tangan (hand line), dan pancing tonda (trolling line).

Menurut Kesteven (1973) pengembangan usaha perikanan harus mempertimbangkan aspek-aspek bio-technico-sosio-economicapproach. Oleh karena itu ada empat aspek yang harus diperhatikan dalam pengembangan suatu jenis alat tangkap ikan, salah satunya adalah aspek sosial, dapat diterima oleh masyarakat nelayan. Kriteria sosial lainnya adalah alat tangkap tersebut tidak membahayakan nelayan lain dan orang lain di laut, sesuai dengan peraturan yang berlaku, ikan yang tertangkap legal, dan tidak menimbulkan konflik dengan kegiatan lainnya (Purbayanto dkk, 2010).

Penelitian ini mengkaji bagaimana kegiatan penangkapan ikan tuna (Thunnus sp) prospek pengembangan alat tangkap di kaji dari aspek sosial, di Desa Yainuelo Kecamatan Amahai Kabupaten Maluku Tengah.

\subsection{Tujuan Penelitian}

Adapun tujuan penelitian ini adalah untuk mengevaluasi aspek sosial kegiatan penangkapan ikan Tuna dan kemungkinan pengembangan alat tangkap ikan Tuna.

\subsection{Kegunaan Penelitian}

Hasil penelitian ini dapat dijadikan bahan informasi bagi pengembangan perikanan tangkap ikan Tuna di Desa Yainuelo Kecamatan Amahai Kabupaten Maluku Tengah.

\section{METODE PENELITIAN}

\subsection{Waktu dan Lokasi Penelitian}

Penelitian ini dilaksanakan bulan November 2013, dengan lokasi pada Desa Yainuelo. Penentuan lokasi penelitian tersebut dilakukan secara purposive dengan pertimbangan bahwa desa tersebut nelayannya melakukan kegiatan penangkapan ikan tuna dengan menggunakan alat tangkap pukat cincin (purse seine), pancing tangan (hand line), dan pancing tonda (trolling line).

\subsection{Teknik Penentuan Sampel}

Pengambilan sampel dilakukan dengan teknik convenience (hapzard atau accidental) yaitu prosedur memilih responden yang paling mudah tersedia, sembarang atau kebetulan ditemui (Juanda, 2007). Jumlah sampel dalam penelitian ini adalah 20 orang nelayan ikan tuna yang terdiri dari 3 orang nelayan pancing tangan (hand line), 4 orang nelayan pukat cincin (purse seine) dan 13 orang nelayan pancing tonda (trolling line).

\subsection{Teknik Pengumpulan Data}

Berdasarkan tujuan penelitian, maka data yang dikumpulkan dalam penelitian ini terdiri atas dua sumber data data primer dan data sekunder.

1. Data primer, yaitu data yang diperoleh dari pengamatan langsung di lapangan, dengan metode wawancara yang mendalam (dept interview) dengan responden berdasarkan daftar pertanyaan (kuisioner) yang telah disusun sesuai dengan keperluan analisis dan tujuan penelitian.

2. Data sekunder, yaitu data penunjang yang diperoleh dari intansi terkait yang berhubungan dengan materi penelitian (Dinas Perikanan dan Kelautan dan Badan Pusat Statistik).

\subsection{Analisis Data}

Analisis yang dipakai untuk aspek sosial adalah analisis kualitatif dan kuantitatif, yang didasarkan pada kriteria-kriteria sosial masyarakat nelayan terhadap performa alat tangkap dengan menggunakan pendapat responden. Untuk mengukur sikap responden terhadap performa alat tangkap digunakan skala likert. Nilai dari tiap kriteria diperoleh dari jumlah hasil perkalian antara persentase responden yang memilih suatu jawaban dengan skor yang diberikan untuk jawaban tersebut.

Data yang dikumpulkan untuk aspek sosial antara lain : 
- Penerimaan masyarakat nelayan terhadap suatu jenis alat tangkap (Tingkat pendidikan dan ketrampilan nelayan).

- Penyerapan tenaga kerja per unit penangkapan

- Kemampuan nelayan menjangkau investasi unit penangkapan

- Tidak menimbulkan konflik

Setelah diperoleh nilai dari semua kriteria, maka dilakukan standarisasi nilai dengan metode fungsi nilai (Mangkusubroto dan Trisnadi, 1985) dengan rumus sebagai berikut :

$$
\begin{aligned}
& V i(X i)=\frac{X i-X o}{X 1-X o} \\
& V(A)=\sum V i(X i) \\
& \mathbf{i} \quad=1,2,3, \ldots \ldots ., \mathbf{n}
\end{aligned}
$$

Dimana :

$$
\begin{aligned}
& V i(X i) \quad: \quad \text { Fungsi nilai alternatif } \mathrm{i} \\
& \text { pada kriteria ke-i } \\
& X o \quad: \text { Nilai Terburuk pada Kriteria } \mathrm{X} \\
& X i \quad: \text { Nilai dari kriteria ke-i } \\
& X 1 \quad: \text { Nilai terbaik dari kriteria } \mathrm{X} \\
& V(A): \text { Fungsi Nilai dari Alternatif } \mathrm{A} \\
& V i \quad: \text { Fungsi Nilai dari Alternatif pada } \\
& \text { Kriteria ke-i }
\end{aligned}
$$

Urutan alat tangkap yang sesuai untuk digunakan ditetapkan dari alternatif yang mempunyai fungsi nilai tertinggi ke alternatif dengan fungsi nilai terendah.

Karena $\mathrm{V}$ adalah fungsi nilai yang mencerminkan preferensi pengambil keputusan maka alternatif yang terbaik adalah alternatif yang memberikan nilai $\mathrm{V}(\mathrm{X})$ tertinggi merupakan alat tangkap ikan yang terpilih untuk dikembangkan di Desa Yainuelo Kecamatan Amahai.

Adapun asumsi yang digunakan adalah bahwa dari hasil determinasi yang dilakukan terhadap unit penangkapan ikan tuna yang dioperasikan nelayan di Desa Yainuelo, nilai skor terbesar diprioritaskan untuk dikembangkan dibandingkan alat tangkap yang lebih kecil skor nilainya.

\section{HASIL DAN PEMBAHASAN}

\subsection{Aspek Sosial}

Hasil survei yang dilakukan terhadap kegiatan perikanan tangkap ikan tuna di Desa Yainuelo diperoleh tiga jenis alat tangkap yang digunakan oleh nelayan setempat, yaitu: (1) Pancing Tonda (Trolling Line), (2) Pancing tangan (Hand Line), dan (3) Pukat Cincin (Purse Seine). Tinjauan terhadap aspek sosial difokuskan pada tingkat penerimaan nelayan terhadap suatu jenis alat tangkap, daya serap tenaga kerja dari setiap unit alat tangkap, pendapatan bersih dan tidak menimbulkan konflik.

\subsubsection{Penerimaan Nelayan Terhadap Jenis Alat} Tangkap

Hasil analisis sosial terhadap masingmasing alat tangkap menunjukan bahwat nilai untuk kriteria penerimaan nelayan terhadap alat tangkap pancing tonda (trolling line), pukat cincin (purse seine), dan pancing tonda (hand line) masing-masing memiliki urutan nilai yaitu : 376,92., 350,00., dan 300,00. Dari nilai tersebut diketahui bahwa nelayan lebih menyukai pancing tonda dibandingkan kedua alat tangkap lainnya, hal ini disebabkan alat tangkap ini telah digunakan turun temurun oleh nelayan setempat untuk menangkap ikan tuna sehingga teknik pengoperasiannya sudah dikuasai. Operasi penangkapannya lebih mudah karena bisa dilakukan sendiri. Selain itu alat tangkap ini memberikan manfaat ekonomi yang lebih tinggi dibandingkan alat tangkap lainnya.

Tingkat penerimaan nelayan terhadap alat tangkap pancing tangan (hand lines) sangat rendah hal ini disebabkan hasil produksinya sangat rendah sehingga nelayan di lokasi penelitian pada umumnya jarang menggunakan alat tangkap ini.

3.1.2. Jumlah Tenaga Kerja per Unit Alat Tangkap dan Pendapatan Nelayan per Unit Alat Tangkap

Berdasarkan kriteria penyerapan jumlah tenaga kerja per unit alat tangkap, maka alat tangkap pukat cincin ( purse seine) memiliki nilai tertinggi dibandingkan alat tangkap pancing tonda( trolling line) dan pancing tangan (hand lines). Jumlah tenaga kerja yang ikut dalam satu unit pukat cincin (purse seine) di Desa Yainuelo adalah 15 orang. Mallawa et al, (2012) melaporkan bahwa di Sulawesi Selatan satu unit pukat cincin ( purse seine) dengan kapasitas kapal 10 - 15 GT jumlah awak berkisar 8-13 orang. Tenaga kerja tersebut sangat besar peranannya pada saat setting dan 


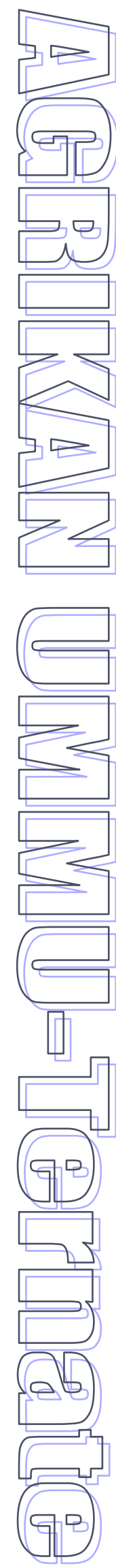

hauling karena nelayan pukat cincin (purse seine) masih menggunakan tenaga pada waktu pengangkatan jaring. menurut Nomura (1975) dalam Mallawa et al, (2012) bahwa untuk tuna purse seine, jaring memerlukan setting yang sangat cepat dan sinking speed yang tinggi, serta twine harus kaku dan tegar agar dapat menahan gaya-gaya yang timbul disebabkan oleh gelepar-gelepar tuna yang tertangkap.

Alat tangkap pancing tonda (trolling line) dan pancing tangan (hand line) tingkat penyerapan tenaga kerjanya masing-masing 3 orang dan 1 orang per unit alat tangkap. Hal ini disebabkan kedua jenis alat tangkap tersebut operasionalnya sangat sederhana sehingga tidak memerlukan jumlah tenaga kerja yang banyak. Selain itu kapasitas kapal yang digunakan hanya 5 GT sehingga tidak memungkinkan untuk menampung awak dalam jumlah yang banyak.

Indikator sosial lainnya adalah pendapatan bersih nelayan per bulan per unit alat tangkap hal ini untuk menilai apakah usaha tersebut menguntukan. Hasil analisis diperoleh rata-rata pendapatan bersih nelayan per bulan per unit alat tangkap yang tertinggi yaitu, pukat cincin (purse seine) Rp. 42.165.385,57. Kemudian pancing tonda (trolling line) Rp.29.889.862,84 dan terendah yaitu pancing tangan (hand line) Rp. 14 .175.132,28.

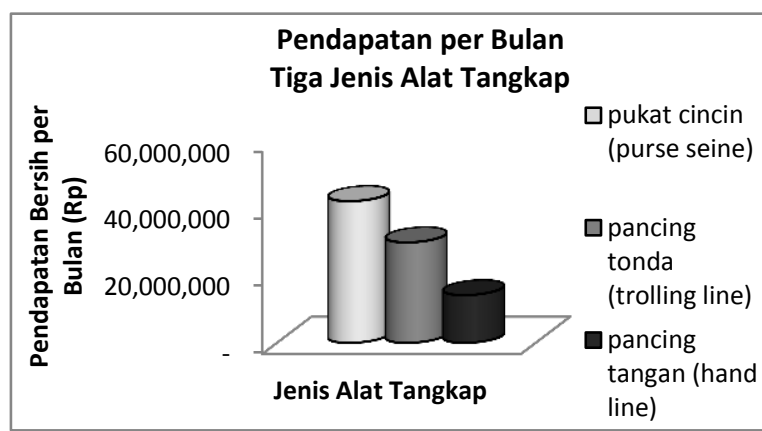

Gambar 1. Pendapatan Bersih per Bulan Tiga Jenis Alat Tangkap

\subsubsection{Kemampuan Nelayan Berinfestasi}

Tingkat kemampuan nelayan berinvestasi pada ketiga jenis alat tangkap berbeda-beda. Kemampuan nelayan menjangkau investasi pada alat tangkap pancing tangan (hand lines) sangat tinggi ini ditunjukan dengan nilai 433,34. Sedangkan tingkat investasi yang sedang pada alat tangkap pancing tonda (trolling line) dan terendah pada alat tangkap pukat cincin (purse seine).

Tingginya kemampuan nelayan menjangkau investasi pada alat tangkap pancing tangan (hand lines) disebabkan modal yang dibutuhkan untuk mendapatkan satu unit alat tangkap sangat kecil dibandingkan kedua alat tangkap lainnya. Untuk membuat satu unit alat tangkap pancing tangan (hand line) dibutuhkan biaya investasi rata-rata Rp.29.666.666,67 Biaya tersebut jika dibandingkan dengan biaya untuk membuat alat tangkap pancing tonda dan purse seine maka masih tergolong rendah. Berdasarkan hasil wawancara, biaya investasi rata-rata yang dibutuhkan untuk satu unit pancing tonda (trolling line) adalah Rp. 45.461.538,46. sedangkan untuk satu unit purse seine dibutuhkan biaya investasi rata-rata $\mathrm{Rp}$. 645.000.000 (Lampiran 2). Hasil penelitian Nanlohy (2009), melaporkan bahwa untuk membuat satu unit pancing tonda (kapal, alat tangkap dan mesin) dibutuhkan biaya $\mathrm{Rp}$. 36.500 .000

\subsubsection{Tidak Menimbulkan Konflik}

Penggunaan alat tangkap yang berbeda untuk menangkap jenis ikan yang sama sejauh ini tidak menimbulkan konflik yang berarti dalam tatanan kehidupan masyarakat nelayan setempat. Hal ini disebabkan tingginya hubungan kekerabatan antara masyarakat akibat ikatan perkawinan maupun ikatan etnis.

Menurut Kusnadi (2009), pada dasarnya konflik di antara nelayan disebabkan persaingan memperebutkan daerah penangkapan (fishing ground) dan pelanggaran jalur-jalur penangkapan. Bagi nelayan setempat meskipun fishing groundnya sama jarang terjadi konflik. Selain itu nelayan pada umumnya melakukan penangkapan di rumpon masing-masing, atau di rumpon lain yang pembagian hasilnya satu bagian untuk pemilik rumpon.

\subsection{Standarisasi Nilai Kriteria Aspek Sosial}

Standarisasi nilai keseluruhan kriteria aspek sosial dapat dilihat pada tabel 1. Hasil tersebut menunjukan bahwa pancing tonda (trolling line) merupakan alat tangkap unggulan pada urutan prioritas utama. Urutan 
prioritas utama pada aspek sosial menunjukan bahwa trolling line atau pancing tonda dapat diterima oleh masyarakat karena alat tangkap ini telah dikuasai dengan baik, karena nelayan lebih mudah dalam penguasaan teknik pengoperasiaannya karena alat tangkap ini telah dikuasai secara turun temurun. investasinya mampu dijangkau oleh nelayan serta dapat memberikan keuntungan yang maksimal. Diikuti oleh alat tangkap pukat cincin (purse seine) dan pancing tangan (hand line). Dengan demikian berdasarkan aspek sosial prioritas pengembangan alat tangkap yang paling tepat di Desa Yainuelo adalah pancing tonda (trolling line).

Tabel 1 . Standarisasi Nilai Aspek Sosial dari Setiap Jenis Alat Tangkap

\begin{tabular}{|c|l|c|c|c|c|c|c|c|c|c|c|}
\hline No & Jenis Alat Tangkap & $\mathbf{X}_{\mathbf{1}}$ & $\mathbf{V}_{\mathbf{1}}\left(\mathbf{X}_{1}\right)$ & $\mathbf{X}_{\mathbf{2}}$ & $\mathbf{V}_{\mathbf{2}}\left(\mathbf{X}_{2}\right)$ & $\mathbf{X}_{3}$ & $\mathbf{V}_{\mathbf{3}}\left(\mathbf{X}_{3}\right)$ & $\mathbf{X}_{4}$ & $\mathbf{V}_{\mathbf{4}}\left(\mathbf{X}_{4}\right)$ & $\mathbf{V}(\mathbf{A})$ & $\mathbf{U P}$ \\
\hline 1. & $\begin{array}{l}\text { Pancing tangan } \\
\text { 2. }\end{array}$ & 300,00 & 0,00 & 1 & 0,00 & $14.175 .132,28$ & 0,00 & 433,34 & 0,90 & 0,90 & 3 \\
3. & $\begin{array}{l}\text { Pund Line) } \\
\text { Pukat cincin }\end{array}$ & 350,00 & 0,65 & 15 & 1,00 & $42.165 .385,57$ & 1,00 & 100,00 & 0,00 & 2,65 & 2 \\
(Purse Seine) & $\begin{array}{l}\text { Pancing Tonda } \\
\text { (Trolling line) }\end{array}$ & 376,92 & 1,00 & 3 & 0,14 & $29.889 .862,84$ & 0,56 & 469,24 & 1,00 & 2,70 & 1 \\
\hline
\end{tabular}

Sumber : Data Primer setelah Diolah, 2013 Keterangan :

$$
\begin{aligned}
& X_{1}=\text { Nilai berdasarkan penerimaan alat tangkap oleh nelayan } \\
& X_{2}=\text { Jumlah tenaga kerja per unit alat tangkap } \\
& X_{3}=\text { Pendapatan bersih nelayan per unit alat tangkap per bulan } \\
& X_{4}=\text { Nilai berdasarkan kemampuan nelayan menjangkau investasi }
\end{aligned}
$$

\section{PENUTUP}

\subsection{Kesimpulan}

Berdasarkan hasil analisis, maka dapat ditarik kesimpulan sebagai berikut :

1. Kegiatan penangkapan ikan tuna dengan menggunakan alat tangkap pancing tonda (trolling line) dan pukat cincin dapat diterima secara sosial. Secara sosial standar nilai alat tangkap pancing tonda 2,70 dan pukat cincin 2,65.

2. Alat tangkap ikan tuna yang baik untuk dikembangkan di Desa Yainuelo berdasarkan kriteria aspek sosial pancing tonda (trolling line).

\subsection{Saran}

Sesuai dengan hasil studi maka pengembangan alat tangkap pancing tonda (trolling line) perlu mendapat prioritas pengembangan. Prioritas pengembangan hendaknya memperhatikan keseimbangan dan ketersediaan sumberdaya ikan tuna dan lingkungan ekologisnya. Oleh karena itu, pengembangan alat tangkap perlu mendapat dukungan dari masyarakat dan pemerintah.

\section{DAFTAR PUSTAKA}

Badan Pusat Statistik. 2012. Maluku Tengah dalam Angka. BPS Maluku Tengah Juanda, B. 2007. Metodologi Penelitian Ekonomi dan Bisnis. IPB Press, Bogor.

Kusnadi, 2009. Keberdayaan Nelayan dan Dinamika Ekonomi Pesisir. Ar-Ruzz Media, Yogyakarta. Mankusubroto dan Trisnadi. 1985. Analisa Keputusan. Pendekatan Sistem dalam Manajemen Usaha dan Proyek. Ganeca Exact, Bandung.

Mallawa, A. dan Najamuddin. 2003. Pemanfaatan Sumberdaya Perikanan berkelanjutan. Makalah pada Seminar Nasional Pemanfaatan Sumberdaya Perikanan Bertanggungjawab dan Berbasis Masyarakat, Badan Eksekutif Mahasiswa Perikanan UNHAS.

Nanlohy, A.C. 2009. Evaluasi Alat Tangkap Ikan Pelagis yang Ramah Lingkungan di Perairan Maluku dengan Menggunakan Prinsip CCRF (Code of Conduct for Responsible Fisheries). Jurnal Ilmu Hewani Tropika Vol. 2 No.1 Juni 2013. ISSN: 2301-7783

Purbayanto dkk, 2010. Fisiologi E Tingkah Laku Ikan pada Perikanan Tangkap. Penerbit IPB Press. Kampus IPB Taman Kencana Bogor. 